\title{
Article \\ Nano-Modified Meta-Aramid Insulation Paper with Advanced Thermal, Mechanical, and Electrical Properties
}

\author{
Xiying Qian ${ }^{1}$, Long Yue ${ }^{2}$, Keruo Jiang ${ }^{2}$, Hongxue Wang ${ }^{2}$, Jingyin Lai ${ }^{2}$, Hailiang Xia ${ }^{1}$ and Chao Tang ${ }^{3, *}$ \\ 1 Ningbo Transmission \& Transformation Construction Ltd., Ningbo 315000, China; 13306606676@189.cn (X.Q.); \\ hailiyidianba@126.com (H.X.) \\ 2 State Grid Ningbo Electric Power Supply Company, Ningbo 315000, China; yl18858251772@163.com (L.Y.); \\ nbdyjjkr@sohu.com (K.J.); wanghx1025@163.com (H.W.); nblai@sina.com (J.L.) \\ 3 College of Engineering and Technology, Southwest University, Chongqing 400715, China \\ * Correspondence: swutc@swu.edu.cn
}

check for updates

Citation: Qian, X.; Yue, L.; Jiang, K.; Wang, H.; Lai, J.; Xia, H.; Tang, C.

Nano-Modified Meta-Aramid Insulation Paper with Advanced Thermal, Mechanical, and Electrical Properties. Processes 2022, 10, 78. https://doi.org/10.3390/pr10010078 Academic Editor: Andrew S. Paluch

Received: 29 November 2021 Accepted: 23 December 2021 Published: 30 December 2021

Publisher's Note: MDPI stays neutral with regard to jurisdictional claims in published maps and institutional affiliations.

Copyright: (C) 2021 by the authors. Licensee MDPI, Basel, Switzerland. This article is an open access article distributed under the terms and conditions of the Creative Commons Attribution (CC BY) license (https:// creativecommons.org/licenses/by/ $4.0 /$ )

\begin{abstract}
Molecular dynamics simulations were used to analyze the internal mechanism for the observed improvement in performance of nano-modified meta-aramid insulation paper from a microscopic point of view. The results showed that the k-polyphenylsilsesquioxane(PPSQ) modified meta-aramid insulation paper was superior to b-PPSQ modified meta-aramid insulation paper in terms of its thermal stability and mechanical and electrical properties. The analysis of microscopic parameters showed that the stiffness of k-PPSQ was less than that of b-PPSQ, and the hydroxyl groups on the open-loop system were more likely to enter the dispersed system, resulting in higher bonding strength, meta-aramid fiber chains between k-PPSQ molecules, and the formation of hydrogen bonds. Additionally, the nano-enhancement effects of k-PPSQ and b-PPSQ resulted in various improvements, including a reduction in pores between molecules in the blend model, an increase in the contact area, the formation of interfacial polarization, and a reduction in defects at the interface.
\end{abstract}

Keywords: polyphenylsilsesquioxane; meta-aramid insulation paper; thermal stability; nano particles

\section{Introduction}

The growth of global energy transmission networks has necessitated the use of transmission lines with ultra-high voltages, large capacities, and long distances [1,2]. The transformer is core component of ultra-high voltage DC/AC transmission, and its operational safety and stability are very important for the entire transmission network [3]. The development of new materials to improve the heat resistance, operational safety, and reliability of traditional transformers is an important field of research. Research on the microscopic and macroscopic mechanisms and performance has important scientific significance and engineering value [4,5]. The rise of nanotechnology has resulted in significant research efforts and has greatly promoted the understanding and improvement of nanodielectric materials. Nano-dielectrics are promising next-generation high-performance materials [5-8].

The prolonged service life of transformers and the complex electric field distribution in ultra-high voltage transformers mandates high performance requirements from traditional cellulose insulation paper. This has resulted in increased research on transformer insulation and the utilization of new insulation materials [9-11]. Meta-aramid insulation paper has been widely used in many industrial fields, such as for military applications, telecommunications, and transportation because of its good thermal stability, electrical insulation, corrosion resistance, and flame retardancy [12-16]. In particular, meta-aramid insulation paper has gradually replaced traditional cellulose insulation paper in the internal oil-insulation system of transformers.

Polyoctaphenylsilsesquioxane (PPSQ) is a nano-compound that is composed of alternate $\mathrm{Si}-\mathrm{O}-\mathrm{Si}$ bonds that form the main inorganic skeleton, and the $\mathrm{Si}$ atoms are con- 
nected to a phenyl side group $[17,18]$. This special molecular structure allows it to be incorporated into organic polymers, resulting in improved polymer thermal stability after mixing at the molecular level [17-21]; additionally, the mechanical properties [17,18,20-22], electrical properties [4,23], hydrophobicity [21], and flame retardancy [21,22,24] are also further improved.

However, there are few reports on the modification of meta-aramid insulation paper by PPSQ. It is of great engineering practice value to study the performance of transformer insulation paper modified by different structures of nanoparticles in the normal temperature range of transformer aging research. In this work, two different structures of PPSQ were used to modify meta-aramid insulation paper. Through a combination of experimental studies and molecular dynamics (MD) simulations, the effects of the different structures of PPSQ on the properties of the meta-aramid insulation paper and its internal mechanism were investigated.

\section{Thermal Aging Experiment}

The modified insulation paper was prepared, and an accelerated heat aging test was performed at $130{ }^{\circ} \mathrm{C}$. By comparing and analyzing the moisture content, mechanical properties, and breakdown characteristics of different thermally aged papers, the effects of different PPSQ structures on the performance of meta-aramid fibers were explained.

\subsection{Sample Preparation}

Preparation of the samples was carried out via a conventional paper forming method. The fibers and fibrids for preparing the insulation paper were supplied by Yantai Taihe New Materials Co., Ltd. (Yantai, China). The PPSQ raw material was sourced from Sinopharm Chemical Reagent Co., Ltd. (Shanghai, China). Hydrolysis and condensation reactions were carried out to make different structures of PPSQ. The two different structures of PPSQ are shown in Figure 1.
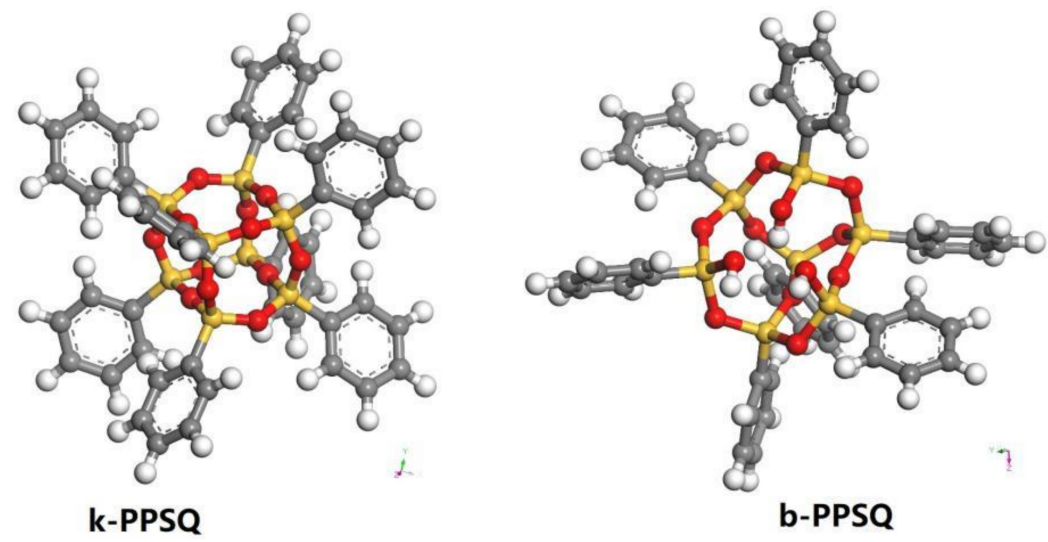

Figure 1. Two different structures of PPSQ.

First, the chopped fibers and the precipitation fibrids were uniformly dispersed using a fiber disintegrator. Next, the uniformly dispersed fiber suspension was formed on a sheet former, and then pressed and dried to obtain the insulation base paper handsheet. Finally, the base paper was hot calendered using a high-temperature calender to obtain the insulation paper handsheet, which is termed as C0. The two different structures of PPSQ were added in deionized water to form a uniform suspension via ultrasonication. This suspension was added with a dispersing aid to the chopped fibers and precipitation fibrid suspension and uniformly dispersed. After mixing, the composite insulation paper handsheet was prepared using the same process described above. The b-PPSQ insulation paper handsheet is referred to as $\mathrm{Cb}$ and the k-PPSQ insulation paper handsheet is referred to as $\mathrm{Ck}$. 
The three types of insulation paper handsheets were placed in Xinjiang Karamay 25\# insulation oil under vacuum immersion for $48 \mathrm{~h}$. An accelerated thermal aging test was conducted in a vacuum aging tank with a test temperature of $130{ }^{\circ} \mathrm{C}$. The sampling times were $0 \mathrm{~d}, 5 \mathrm{~d}, 12 \mathrm{~d}, 23 \mathrm{~d}$, and $31 \mathrm{~d}$.

\subsection{Experiment Results Analysis}

\subsubsection{Moisture Content}

The presence of moisture promotes the aging of oil-paper insulation. Aramid paper consumes water during the aging process, and it will also produce some water and small molecules because of the instability of the hydrolysis reaction. Over time, the moisture diffuses and migrates in the insulation oil, the insulation paper, and to the air, finally reaching a dynamic equilibrium [25]. According to the IEC 60814-1997 standard, the Karl Fischer method was used to measure the moisture content of the three types of insulation paper with different aging times. The results are shown in Figure 2.

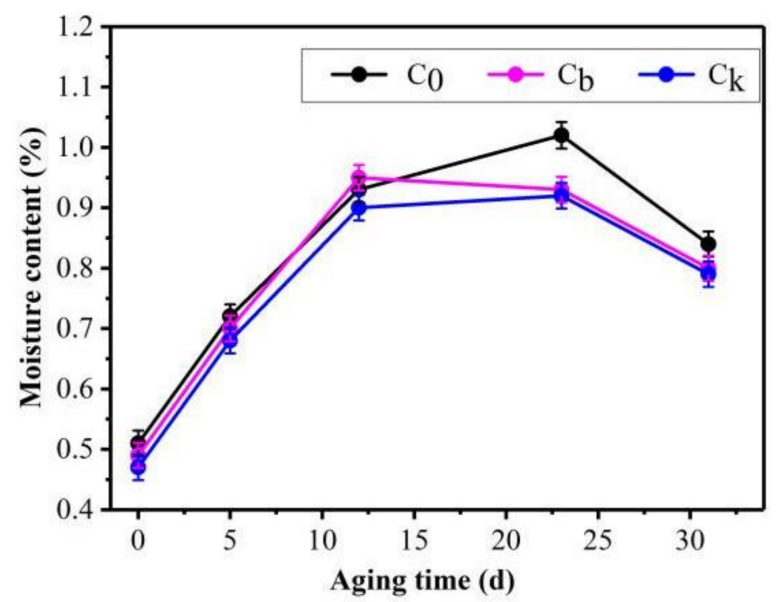

Figure 2. Moisture content of insulation papers with different degrees of aging.

Figure 2 shows that the moisture content of $\mathrm{Ck}$ was slightly lower than $\mathrm{C} 0$ and $\mathrm{Cb}$ throughout the aging process. The reason for this is that the specific surface area of $\mathrm{Ck}$ was larger and the chopped fibers were tightly bonded; hence, the paper had fewer voids and a lower hygroscopicity, resulting in $\mathrm{Ck}$ having a slightly lower moisture content than $\mathrm{C} 0$ and $\mathrm{Cb}$. These results showed that the addition of $\mathrm{Ck}$ can improve the heat resistance of aramid insulation paper.

\subsubsection{Mechanical Properties}

The mechanical properties of the insulation paper were closely related to the length and thickness of the fiber. Generally, as the thermal-aging time progressed, the degree of polymerization of the insulation paper decreased, macroscopically resulting in a decrease in its mechanical strength. The tensile strengths of the three kinds of insulation papers at different aging times were used to characterize the mechanical properties of the insulation paper during aging, and indirectly characterize the degree of aging of the insulation paper. The data were obtained using the AT-L-1 tensile testing machine (Jinan Animeite Instrument Co., Ltd., Shandong, China) according to the ISO 1924-2 standard. The experimental results are shown in Figure 3. 

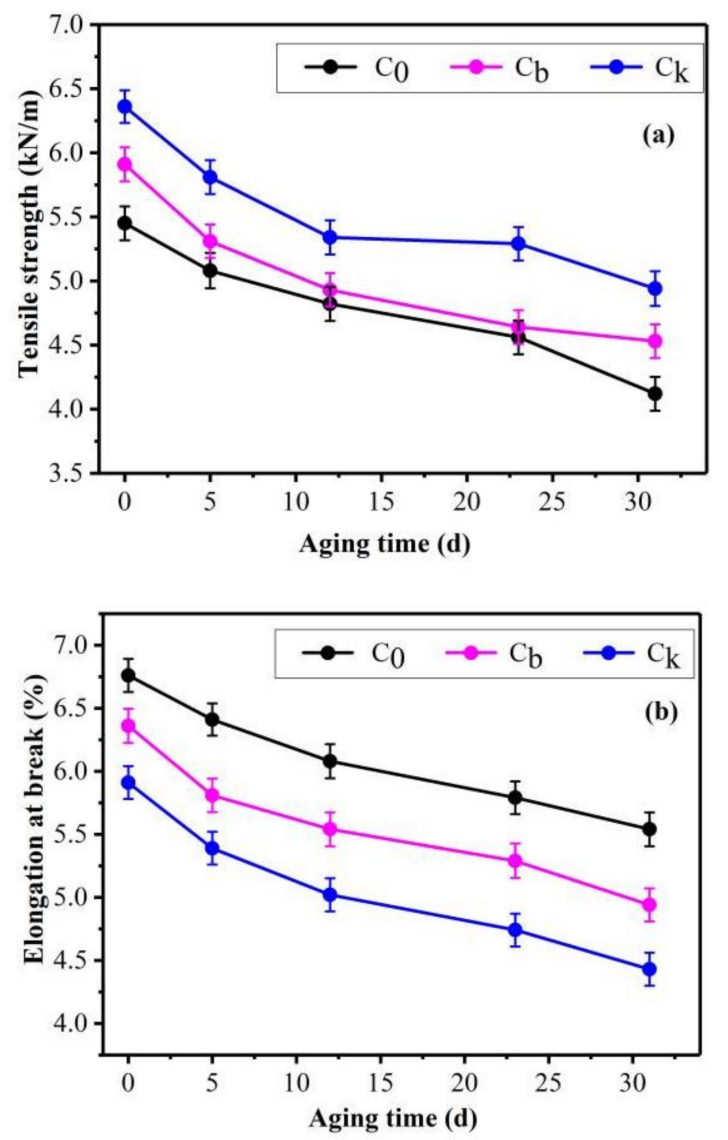

Figure 3. Tensile strength (a) and elongation at break (b) of the insulation papers with different degrees of aging.

It can be seen from Figure $3 a$ that the three kinds of insulation papers had different degrees of tensile strength that varied with the aging time. The decrease in tensile strength for $\mathrm{Cb}$ and $\mathrm{Ck}$ at $0-12 \mathrm{~d}$ was larger than for $\mathrm{C} 0$, while the decrease in tensile strength of $\mathrm{C} 0$ was larger after $23 \mathrm{~d}$. The rate of decrease in the tensile strength of $\mathrm{Cb}$ and $\mathrm{Ck}$ after $12 \mathrm{~d}$ was lower than for $\mathrm{C} 0$. The tensile strength retention rates after $31 \mathrm{~d}$ for $\mathrm{C} 0, \mathrm{Cb}$, and $\mathrm{Ck}$ were $75.6 \%, 76.6 \%$, and $77.7 \%$, respectively. This was because the $\mathrm{Cb}$ and $\mathrm{Ck}$ papers were more compact and had lower porosity, which was beneficial for their thermal-aging resistance. This shows that the addition of PPSQ can effectively improve the anti-aging ability of aramid insulation paper, with Ck demonstrating the largest improvement. Figure $3 \mathrm{~b}$ shows that the elongation of the three papers decreased with increasing thermal-aging duration, indicating that the toughness of the paper deteriorates, and it becomes brittle during the thermal-aging process.

\subsubsection{Breakdown Field Strength}

The breakdown strength of the aramid fiber insulation paper is greatly affected by the tightness and air permeability of the paper. If the tightness is too low, the breakdown strength will be reduced. The overall porosity of aramid insulation paper is larger than other polymers, which also affects its breakdown strength. When the tightness is constant, a lower air insulation paper permeability corresponds with a larger breakdown strength [26]. The breakdown field strengths of the three insulation papers are shown in Figure 4 for different aging times. 


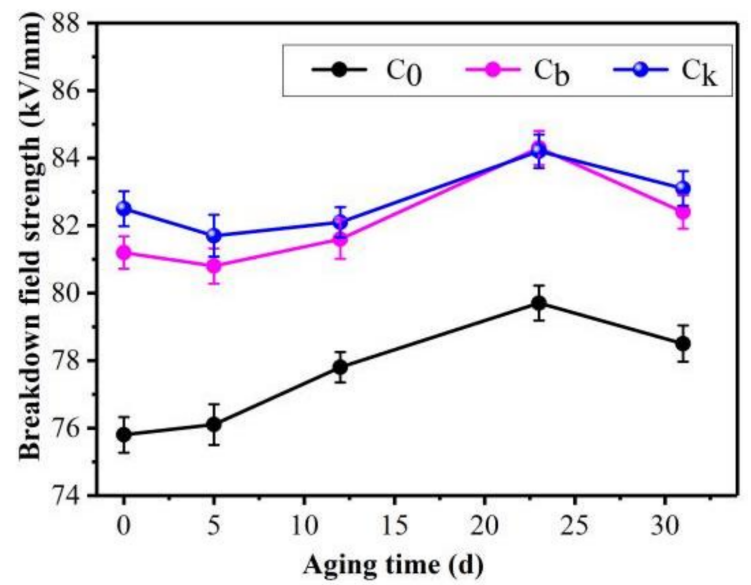

Figure 4. Breakdown field strength of insulation papers with different degrees of aging.

From Figure 4, it can be seen that the breakdown characteristics of the insulation paper did not change with aging time. $\mathrm{C}, \mathrm{Cb}$, and $\mathrm{Ck}$ all increased between 0 and $23 \mathrm{~d}$; however, $\mathrm{Cb}$ and $\mathrm{Ck}$ were generally higher than $\mathrm{C} 0$. This is possibly because there were a large number of traps at the aramid/nanoparticles and nanoparticles/insulation oil interfaces. In the presence of an electric field, the average free path of electrons at the interface with traps is much smaller than that in the bulk. Therefore, the electrons gain less energy, and the breakdown field strength improves.

\section{Molecular Dynamics Simulations}

By characterizing the properties of the modified insulation paper with different degrees of thermal aging, it was shown that PPSQ modified meta-aramid insulation paper has improved thermal, mechanical, and electrical properties, with k-PPSQ demonstrating the best performance. In this section, MD simulations were used to construct a blending model with different structures of PPSQ and meta-aramid insulation paper to analyze the internal mechanisms associated with the alteration of the aramid insulation paper's properties.

\subsection{Model Establishment}

The meta-aramid fiber is a polymer with a molecular weight of 60,000-900,000 [27]. While aramid fiber is artificially synthesized, it has crystalline and amorphous structures as well as cellulose in the natural state. It has been shown that the meta-aramid fiber has a low crystallinity, and the amorphous region comprises $75-80 \%$ of the material [28]. An aramid fiber chain may have to pass through several crystal regions and amorphous regions, so the length of the fiber chain that is actually in the amorphous region may be small. Studies have reported that an amorphous fiber model composed of different fiber chain lengths displays no significant difference in molecular conformation or physicochemical properties [29]. The degree of meta-aramid polymerization of the amorphous zone model was taken as $10[30,31]$, and the initial density of the model was $1.25 \mathrm{~g} / \mathrm{cm}^{3}$. The structure optimization, annealing, and molecular dynamics simulation of the established models were carried out. The simulation details are shown in Figure 5. The software used was Material Studio 5.0, and COMPASS force field was selected in this paper [30-38]. Using b-PPSQ and meta-aramid fibers as an example, a model diagram is shown in Figure 6. 


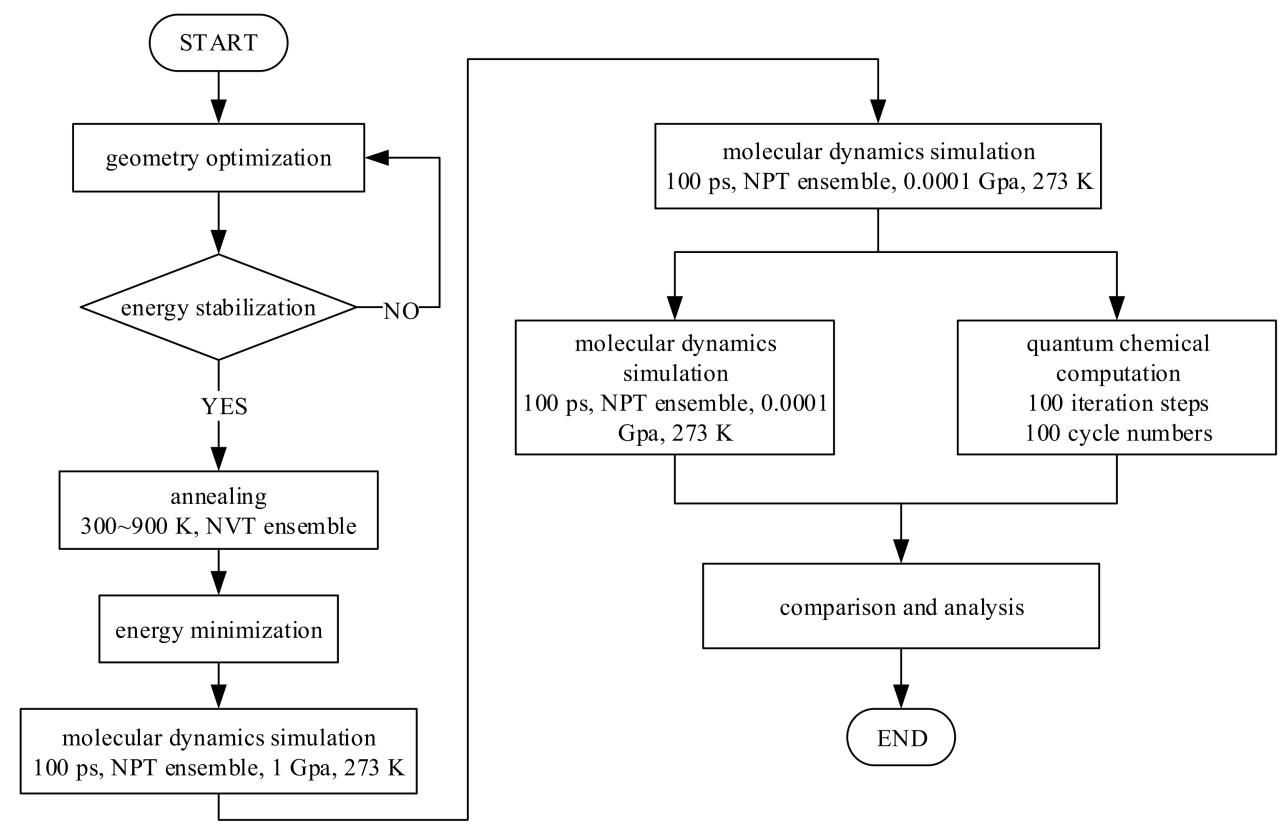

Figure 5. Simulation details.

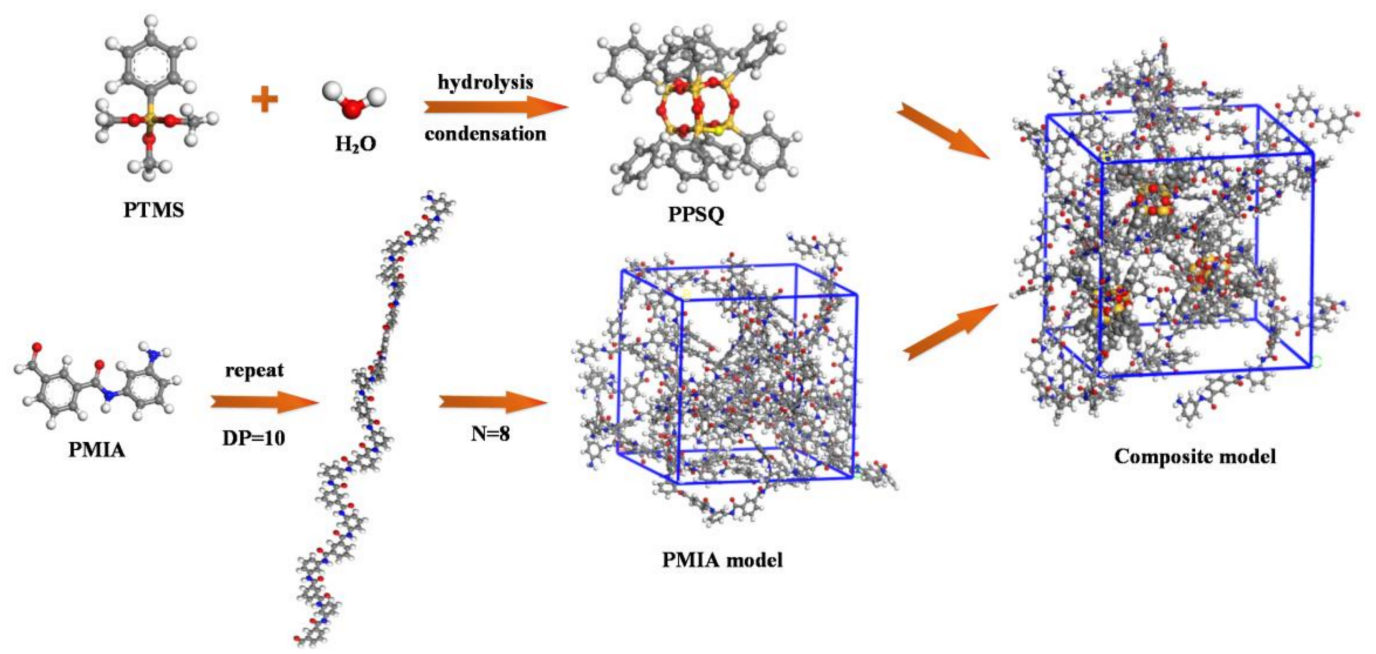

Figure 6. Schematic diagram of the constructed model.

\subsection{Parameter Calculation Results Analysis}

In this part, the investigated micro-parameters, including the glass transition temperature, mechanical properties, dielectric constant, and cohesive energy density (solubility parameters), are presented. The performance improvement of aramid insulation paper with different PPSQ structures was analyzed from the perspective of these four micro-parameters. First, the influence of the thermal stability energy of the nano-modified meta-aramid fiber was analyzed using the volume-temperature curve method to calculate the glass transition temperature value over a large temperature range (303-823 K). Subsequently, the effects of adding different structural nanoparticles on the mechanical, electrical, and physical properties of the meta-aramid fiber were analyzed in the temperature range of 343-423 K (the normal temperature range for a transformer aging study).

\subsubsection{Glass Transition Temperature}

For polymers, the glass transition temperature is used as a criterion for material stability. The most common and reliable method used in research to establish the glass transition temperature is the specific volume-temperature curve method [39]. This method 
was used in this work with a selected temperature range of 303-823 K, and the data were extracted every $40 \mathrm{~K}$. The glass transition temperature curve is plotted and shown in Figure 7.

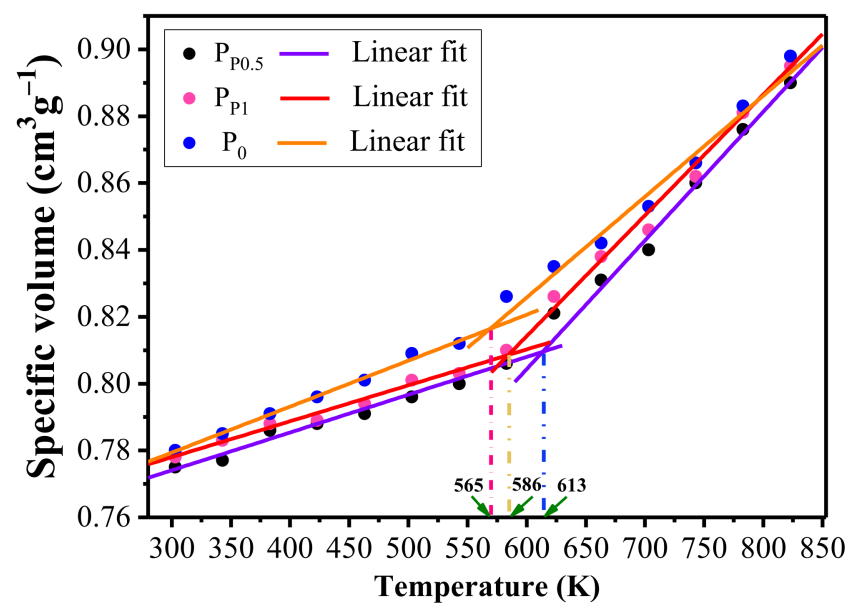

Figure 7. Glass transition temperature for the three models.

From Figure 7, it can be seen that the specific volume of the model increases as the temperature rises, and the three models showed a specific volume jump between $543-583 \mathrm{~K}$ and 583-623 K. After linear fitting, the glass transition temperature of the unmodified model material was $565 \mathrm{~K}$, the glass transition temperature model for the b-PPSQ modified composite was $586 \mathrm{~K}$, and it was $613 \mathrm{~K}$ for the k-PPSQ modified composite. The temperature for the modified material was higher than that for the unmodified material, indicating that the addition of PPSQ could increase the glass transition temperature material. In addition, the glass transition temperature was closely related to the mechanical properties and thermal stability of the material. The glass transition temperature of the k-PPSQ modified composite model was higher than the b-PPSQ composite; hence, k-PPSQ can improve the thermal stability of the meta-aramid insulation paper the most.

\subsubsection{Mechanical Parameters}

It is known from elastic mechanics that the most general relationship between the stress and strain of a solid material can be expressed using the generalized Hooke's law. The mechanical parameters of the material can be calculated according to its elastic mechanics, including the bulk modulus $(\mathrm{K})$, shear modulus $(\mathrm{G})$, elastic modulus (E), Poisson's ratio (v), and Cauchy pressure $(\mathrm{C} 12-\mathrm{C} 44)$. These parameters can be used to characterize the different mechanical properties of the material [40]. The calculation results are shown in Figure 8.

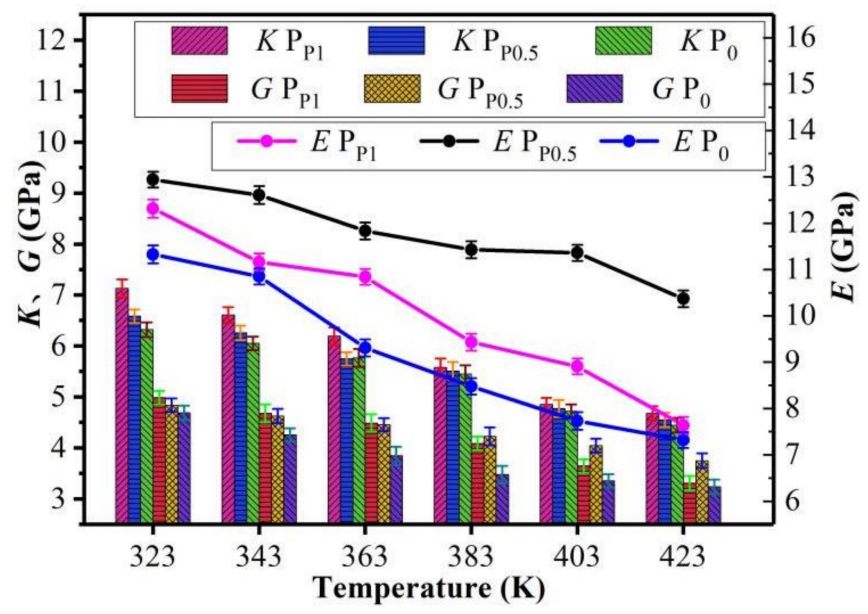

Figure 8. Mechanical parameters of three models. 
It can be seen from Figure 8 that the K, G, and $E$ modulus values of the three modified models show a negative trend with increasing operating temperature. However, the modulus values for the two modified models were better than the unmodified model. It can be seen that the variation of the $\mathrm{K}$ and $\mathrm{G}$ modulus of the b-PPSQ modified composite was relatively optimal among the three models, indicating that the compressibility of the meta-aramid fiber modified by b-PPSQ decreased and its ability to resist a cutting stress was enhanced. At the same time, the E modulus values of the k-PPSQ modified composite increased by $5.1 \%, 12.9 \%, 9.2 \%, 21.2 \%, 27.5 \%$, and $35.8 \%$ compared with the b-PPSQ modified composite. This shows that the meta-aramid fiber modified by k-PPSQ had increased rigidity and the ability to resist deformation.

The Poisson's ratio is the mutual influence of the amount of deformation of the material in different directions, and it has no relationship with the ease of deformation. As shown in Table 1, the k-PPSQ modified composite had the smallest Poisson's ratio over several selected temperatures, and the mutual influence of the material's deformation in different directions can be considered to be small. The Cauchy pressure reflects the ductility of the material. As shown in Table 2, the Cauchy pressure values for the two modified composites were positive, indicating that the meta-aramid(PMIA) fiber itself was ductile. The addition of different PPSQ molecules enhanced the ductility of the PMIA fiber, with the k-PPSQ modified material demonstrating the largest improvement.

Table 1. Poisson's ratio of the two blending models at different temperatures.

\begin{tabular}{ccccccc}
\hline & $\mathbf{3 2 3} \mathbf{K}$ & $\mathbf{3 4 3} \mathbf{K}$ & $\mathbf{3 6 3} \mathbf{K}$ & $\mathbf{3 8 3} \mathbf{K}$ & $\mathbf{4 0 3} \mathbf{K}$ & $\mathbf{4 2 3} \mathbf{K}$ \\
\hline Pure & 0.2714 & 0.2753 & 0.2773 & 0.2850 & 0.2556 & 0.2575 \\
b-PPSQ & 0.2346 & 0.2471 & 0.2569 & 0.2423 & 0.2344 & 0.2519 \\
k-PPSQ & 0.1369 & 0.1252 & 0.1392 & 0.1471 & 0.1404 & 0.1332 \\
\hline
\end{tabular}

Table 2. Cauchy pressure of the two blending models at different temperatures.

\begin{tabular}{ccccccc}
\hline & 323 K & 343 K & 363 K & 383 K & 403 K & 423 K \\
\hline Pure & 0.4599 & 0.8398 & 0.8279 & 1.2232 & 1.2196 & 0.9602 \\
b-PPSQ & 1.1545 & 1.0489 & 1.3799 & 1.4322 & 1.3118 & 1.9324 \\
k-PPSQ & 2.8777 & 2.8195 & 2.7404 & 2.7958 & 2.9159 & 2.8411 \\
\hline
\end{tabular}

After analysis of the parameters, including K, G, E, v, and C12-C44, the mechanical properties of the two modified models showed a negative trend with increasing temperature. The mechanical properties of the k-PPSQ modified material were significantly improved compared with the b-PPSQ modified material. Meta-aramid is a linear macromolecule composed of a phthalamine group interconnected with a meta-phenyl group. A large number of hydrogen bonds form between the phthalamine groups on adjacent molecular chains, and the hydrogen bonds are arranged in two planes. The formation of these strong hydrogen bonds give it a stable chemical structure, excellent mechanical properties, thermal stability, and electrical insulation properties [41,42]. Furthermore, the interaction between the polymer and the nanoparticles creates an internal barrier against rotation of the polymer segment, which improves its mechanical properties. The Si-OH bond on the k-PPSQ silicon oxy-chain has a lower viscous activation energy, which results in mutual compensation of the $\mathrm{d} \pi-\mathrm{p} \pi$ bond between $\mathrm{Si}-\mathrm{O}$ and mutual compensation between the Si-O dipoles [43], eventually resulting in the stiffness of k-PPSQ becoming less than that of b-PPSQ. Moreover, the hydroxyl groups on the ring-opening system are more likely to enter the dispersed system, resulting in a reduction in the pores between the molecules and facilitating the formation of intermolecular hydrogen bonds; this results in improved mechanical properties and thermal stability of the material [44]. 


\subsubsection{Dielectric Constant}

The dielectric constant can reflect the dielectric relaxation processes inside the material; that is, the response of the dielectric to the applied electric field [45]. Dielectric relaxation can be used to probe the structure of a polymer and the properties of related materials. The study of the space charge in solids and defects in crystals can provide significant insights into a material, and the aging of materials and devices are also related to long-term relaxation effects.

The dielectric constants of the two composite models were simulated using the Perl programming language. Perl language is a calculation language compiled based on the corresponding theory, which is a common method in molecular dynamics simulation. The dielectric constant was calculated based on the Formula (1):

$$
e s p=\frac{M}{V \cdot E \cdot e s p 0}
$$

where esp is the dielectric constant, $M$ is total dipole moment (in the direction of the field), $E$ is electric field strength, $V$ is the volume of the box, and esp 0 is vacuum permittivity.

The electric fields were set at $0.007 \mathrm{v} / \AA, 0.008 \mathrm{v} / \AA$, and $0.009 \mathrm{v} / \AA$. The calculated dielectric constants are shown in Figure 9. It can be seen from the figure that the dielectric constant of the k-PPSQ modified composite was generally lower than that of the b-PPSQ composite. Under the same electric field, the two materials first showed an increase and then a decrease with increasing operating temperature. At the same temperature, the two composites showed a negative trend with increasing electric field. Overall, the dielectric constant of k-PPSQ was lower than that of b-PPSQ at the same temperature and electric field. On the one hand, as the temperature increases, the relaxation time $\tau$ decreases, and the relaxation polarization gradually follows the change in the electric field, thereby increasing the polarization; hence, the dielectric constant gradually increases [46]. On the other hand, because of the nano-scale effects of k-PPSQ and b-PPSQ, an interfacial polarization region forms and there are strong interactions between the polymer molecules and the nanoparticles at the bonding layer in the interface region of the model. This may hinder rotation of the polar polymer chains or side groups in the region and effectively reduce the carrier density and mobility. At the same time, the addition of nanoparticles shortens the average free path of the carriers; the interfacial region of the nanoparticles reduces the dynamic properties of the polymer molecular chain, acting as a deep trap to weaken the lossy polarization caused by chemical groups in the polymer, which further affects the dielectric loss and conductance [47-50].

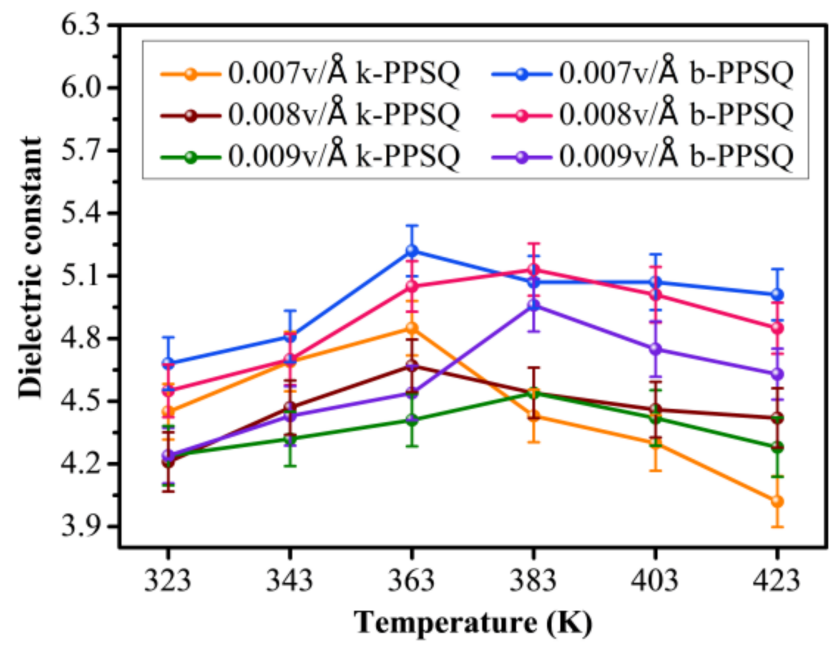

Figure 9. Dielectric constants of two models at different temperatures. 
Compared with some other commonly used insulation materials, meta-aramid insulation paper has excellent electrical properties. Its dielectric constant is 1.5-2.5, which is close to the dielectric constant of air [28]. The organic $\mathrm{C}_{6} \mathrm{H}_{5}$ group in PPSQ has low polarity and large steric hindrance effects, and the Si-O-Si scaffold has a cage structure, which forms intrinsic pores in the material; therefore, the PPSQ-based material has a low dielectric constant $(2.5-3)[17,51]$. According to the electric polarization model, if a medium in a mixture has a large dielectric constant, the degree of polarization of the mixture will increase [52]; in addition, under ideal simulation conditions, a single-direction electric field is used, which results in a determined dielectric constant that is larger than the actual value.

\subsubsection{Cohesive Energy Density and Solubility Parameters}

The cohesive energy density (CED) is defined as the energy required to overcome the intermolecular force of vaporization for $1 \mathrm{~mol}$ of aggregates per unit volume [53,54]. In general, the presence of a highly polar group in a molecule increases the intermolecular forces, and results in a larger cohesive energy and vice versa. The cohesive energy can also be used as a rough indicator to determine the thermal and mechanical properties of materials. A larger cohesive energy results in a larger glass transition temperature and modulus of elasticity [55]. The solubility parameters (Sp) and cohesive energy densities of the three models are shown in Figure 10.

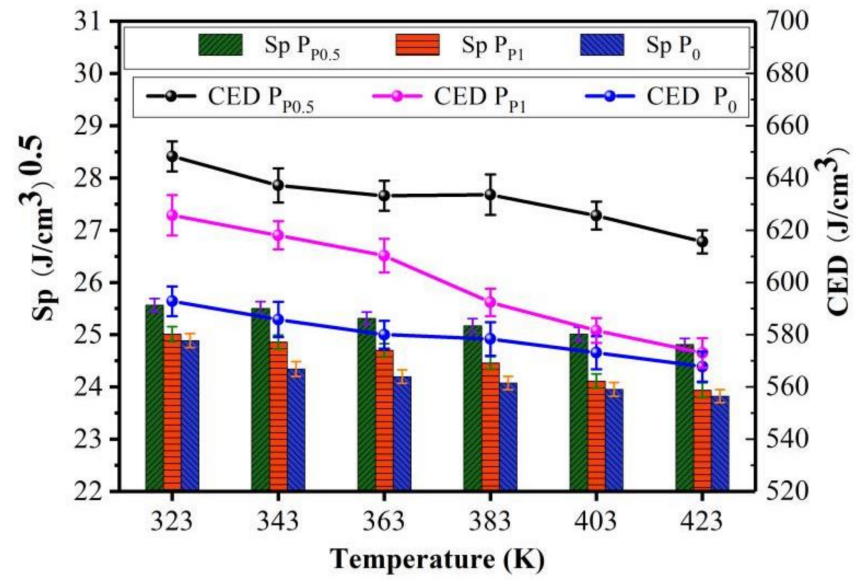

Figure 10. Solubility parameters (Sp) and cohesive energy densities (CED) of the three models at different temperatures.

As shown in Figure 10, the Sp for both models decreased with increasing temperature; these results indicate that the compatibility between the models decreases as the temperature rises. The solubility of the k-PPSQ modified model was slightly higher than that of the b-PPSQ-based material. This is because of the more dispersed distribution of free volume, which can be attributed to the increase of temperature and the resulting increase in molecular chain motion. The distance between molecules increases and the molecular chain is more dispersed. Strong non-bonding interactions are present between the $\mathrm{Si}-\mathrm{OH}$ bond on k-PPSQ and the $\mathrm{C}-\mathrm{N}$ and $\mathrm{C}=\mathrm{O}$ bonds on the meta-aramid fiber. The large bond strength requires more energy to break, and there is a stronger binding effect with the surrounding medium. The PPSQ monomer is in the nanometer scale and has a nano-enhancement effect, resulting in a large available contact area, which allows the PPSQ matrix to be tightly bound to the polymer and makes the meta-aramid fiber chain tighter. The space for movement of the fiber chain is relatively low and the movement strength of the aramid fiber chain is suppressed; the mutual permeability of the two substances increases and mixing at the supramolecular level can be achieved, resulting in an enhanced interfacial bonding force. This is beneficial for improved transfer stress and prevents performance loss, such as by phase delamination, and improves compatibility between the fibers. 
In addition, it can be seen from Figure 10 that an increase of temperature decreases the CED. Based on the physical meaning of the cohesive energy density, it can be seen that for the same material, an increase in temperature decreases the binding forces reflected by the various intermolecular attractive and repulsive contributions in the model. The CED of the k-PPSQ modified composite was better than that of b-PPSQ modified composite. PPSQ can demonstrably improve the fiber surface roughness and enhance the mechanical binding function. Moreover, the silicon hydroxyl group in the k-PPSQ molecule can chemically react with the matrix and chemical bonds formed at the interface of the composite material, which greatly enhances the bonding between the matrix and k-PPSQ. The addition of $\mathrm{k}$-PPSQ results in better filling of the large original voids in the meta-aramid fiber and acts like a binder; therefore, the CED increases. The increase in the CED indicates that the macrosecondary bonds with hydrogen bond-based interactions between the molecular chains are increased, which is beneficial for maintaining a stable condensed fiber structure. This indicates that the density of the aramid paper structure increases, the fiber molecular chain spacing is shortened, and indicates the presence of hydrogen bonding with the phthalamine group, resulting in a stronger bond between the macromolecules of the aramid paper fiber. The good wettability between the two components can expand the contact area and reduce defects at the interface, which has a significant influence on the properties of the metaaramid fiber composite.

\section{Conclusions}

In this paper, the enhanced properties of PPSQ modified meta-aramid insulation paper with different structures and their microscopic mechanisms were studied. The conclusions were as follows:

1. The macroscopic experimental results showed that, during the aging process, the moisture content of the k-PPSQ modified paper was lower than that of the b-PPSQ modified paper and ordinary insulation paper, which improves its thermal aging resistance. The tensile strength of the k-PPSQ modified paper with thermal aging was higher than that of the b-PPSQ modified paper and ordinary insulation paper, demonstrating a reduced loss of mechanical strength during the aging process. Under an electric field, the addition of k-PPSQ introduced a large number of traps in the interfacial area, which resulted in a reduction of the energy of electrons and increased the breakdown field strength by $5.86 \%$ compared with the unmodified material.

2. MD simulations showed that the addition of k-PPSQ increased the glass transition temperature of meta-aramid fiber and improved the thermal stability of the aramid insulation paper. The stiffness of the k-PPSQ modified paper was less than the paper modified with b-PPSQ. The hydroxyl groups on the ring-opening system were more likely to enter the dispersed system, facilitating the formation of intermolecular hydrogen bonds, which improved the mechanical properties of the composite. The nano-scale size of k-PPSQ and b-PPSQ resulted in increased contact area and interfacial polarization, which reduced defects at the interface, hindered rotation of the polar polymer chains and side groups in the region, and ultimately improved the dielectric constant of the composites.

3. The analysis of intermolecular compatibility showed that because of the nano-scale enhancement, the intermolecular chains of the meta-aramid fibers were more compact, the space for motion was reduced, and the overall motion was restrained. The intimate mixing at the supramolecular level could better transfer stress and prevent the degradation of properties, such as interphase stratification, and increase compatibility between the materials. 


\begin{abstract}
Author Contributions: Conceptualization, X.Q. and L.Y.; Data curation, J.L. and H.X.; Formal analysis, K.J. and H.W.; Writing-original draft, J.L.; Writing-review and editing, H.X. and C.T. All authors have read and agreed to the published version of the manuscript.
\end{abstract}

Funding: This research was funded by Ningbo Transmission \& Transformation Construction Ltd., No. SGZJNBSBD202110010.

Institutional Review Board Statement: Not applicable.

Informed Consent Statement: Not applicable.

Data Availability Statement: The study did not report any data.

Conflicts of Interest: The authors declare no conflict of interest.

\title{
References
}

1. Tang, G.F. R\&D and application of key technologies for HVDC equipment. Power Syst. Technol. 2012, 36, 1-6.

2. Wang, Y.; Luo, Y.; Guan, J.; Ding, R. Dielectric properties of epoxy resin impregnated paper insulation in different stages of partial discharge development. Polym. Compos. 2019, 41, 360-368. [CrossRef]

3. Liao, R.J.; Wang, J.Y.; Yuan, Y. Review on the characteristic of new cellulose insulation paper used in the converter transformer. Trans. China Electrotech. Soc. 2016, 31, 1-15.

4. $\quad$ Li, S.T.; Xie, D.R.; Qu, G.H.; Yang, L.; Min, D.; Cheng, Y. Tailoring interfacial compatibility and electrical breakdown properties in polypropylene basedcomposites by surface functionalized PPSQ. Appl. Surf. Sci. 2019, 478, 451-458. [CrossRef]

5. Lei, Q.Q.; Li, S.T. Several important issues and thinking about engineering dielectrics. High Volt. Eng. 2015, 41, $2473-2480$.

6. Lei, Q.Q. Spatiotemporal multilevel structural and motion characteristics of nano-dielectrics and related discussion. In Proceedings of the Xiangshan Science Conferences of Frontiers and Future of Science, Beijing, China, 23-25 June 2011.

7. Zhou, X.X.; Lu, Z.X.; Liu, Y.M.; Chen, S. Development models and key technologies of future grid in China. Proc. CSEE 2014, 34, 4999-5008.

8. Tanaka, T.; Montanari, G.C.; Mulhaupt, R. Polymer nanocomposites as dielectrics and electrical insulation-perspectives for processing technologies, material characterization and future applications. IEEE Trans. Dielectr. Electr. Insul. 2004, 11, 763-784. [CrossRef]

9. Li, J.Z.; Zhang, Q.G.; Li, Y. Generation process of impurity bridges in oil-paper insulation under DC voltage. High Volt. Eng. 2016, 42, 3901-3908.

10. Zhang, F.Z.; Liao, R.J.; Yuan, Y.; Li, Y.; Peng, Q.; Liu, T. Preparation for low-permittivity insulation paper and its breakdown performance. High Volt. Eng. 2012, 38, 691-696.

11. Du, D.; Tang, C.; Tang, Y.; Yang, L.; Hao, J. Molecular simulation on the mechanical and thermal properties of carbon nanowire modified cellulose insulating paper. Compos. Struct. 2020, 261, 113283. [CrossRef]

12. Bourbigot, S.; Flambard, X. Heat resistance and flammability of high performance fibres: A review. Fire Mater. 2002, 26, 155-168. [CrossRef]

13. Awa, B.; Sebaey, T.A.; Yudhanto, A.; Lubineau, G. Post-Impact flexural behavior of carbon-aramid/epoxy hybrid compositesScienceDirect. Compos. Struct. 2020, 239, 112022.

14. Tang, C.; Li, X.; Tang, J.Y.; Zeng, J.; Xie, Y.J.; Xiong, F.B. Agglomeration mechanism and restraint measures of SiO2 nanoparticles in meta-aramid fibers doping modification via molecular dynamics simulations. Nanotechnology 2019, 31, 165702. [CrossRef] [PubMed]

15. Zhuo, L.; Chen, S.; Xie, F.; Qin, P.; Lu, Z. Toward high thermal conductive aramid nanofiber papers: Incorporating hexagonal boron nitride bridged by silver nanoparticles. Polym. Compos. 2021, 42, 1773-1781. [CrossRef]

16. Wang, Y.; Hu, J.; Zhou, X.S.; Zheng, C.S.; Huang, Y.L.; Chen, X.L.; Du, Y.; Hu, Z.M.; Chen, L.; Liu, Z.F. The study of aramid paper. Pap. Sci. Technol. 2004, 23, 57-59.

17. Baney, R.H.; Itoh, M.; Sakakibara, A.; Suzuki, T. Silsesquioxanes. Chem. Rev. 1995, 95, 1409-1430. [CrossRef]

18. Park, E.S.; Ro, H.W.; Nguyen, C.V.; Jaffe, R.L.; Yoon, D.Y. Infrared spectroscopy study of microstructures of poly(silsesquioxane)s. Chem. Mater. 2008, 20, 1548-1554. [CrossRef]

19. Wang, X.; Wu, L.; Li, J. Preparation of nano poly(phenylsilsesquioxane) spheres and the influence of nano-PPSQ on the thermal stability of poly(methyl methacrylate). J. Therm. Anal. Calorim. 2011, 109, 323-329. [CrossRef]

20. Li, G.Z.; Wang, L.; Toghiani, H.; Daulton, T.L.; Koyama, A.K.; Pittman, J.C.U. Viscoelastic and mechanical properties of epoxy/multifunctional polyhedral oligomeric silsesquioxane nanocomposites and epoxy/ladderlike polyphenylsilsesquioxane blends. Macromolecules 2001, 34, 8686-8693. [CrossRef]

21. Qi, L.; Guo, L.; Teng, Q.; Ye, J.; He, L.; Li, X.; Tuo, X. Polyurethane/polyphenylsilsequiloxane nanocomposite: From waterborne dispersions to coating films. Prog. Org. Coat. 2018, 122, 19-29.

22. Jiang, Y.; Li, X.; Yang, R. Polycarbonate composites flame-retarded by polyphenylsilsesquioxane of ladder structure. J. Appl. Polym. Sci. 2011, 124, 4381-4388. [CrossRef] 
23. Hong, E.-Y.; Lee, S.-H.; Lee, D.-K.; Choi, S.-S.; Baek, K.-Y.; Hwang, S.-S.; Kwon, O.-P. Polyaniline films doped with ladder-type sulfonated polyphenylsilsesquioxane and unusual dependence of their electrical conductivity on temperature. J. Mater. Chem. 2012, 22, 18151-18155. [CrossRef]

24. Zhang, W.; Li, X.; Jiang, Y.; Yang, R. Investigations of epoxy resins flame-retarded by phenyl silsesquioxanes of cage and ladder structures. Polym. Degrad. Stab. 2013, 98, 246-254. [CrossRef]

25. Liao, R.; Sang, F.; Liu, G.; Yang, L. Study on neutral acid and water dissolved in oil for different types of oil-paper insulation compositions of transformers in accelerated ageing tests. Proc. CSEE 2010, 30, 125-131.

26. Lv, J.; Zhan, H.Y.; Jin, H.C. Power transformer insulation paper: Its properties and insulation aging. China Pulp Pap. 2008, 27, $54-58$.

27. Valiyaveettil, S.; Gans, C.; Klapper, M.; Gereke, R. Synthesis and structural study of poly(isophthalamide)s. Polym. Bull. 1995, 34, 13-19. [CrossRef]

28. Jain, A.; Vijayan, K. Thermally induced structural changes in nomex fibers. Bull. Mater. Sci. 2002, 25, 341-346. [CrossRef]

29. Mazeau, K.; Heux, L. Molecular dynamics simulations of bulk native crystalline and amorphous structures of cellulose. J. Phys. Chem. B 2003, 107, 2394-2403. [CrossRef]

30. Zheng, W.; Xie, J.; Zhang, J.; Tang, C.; Zhao, Z. Influence of polymethylsilsesquioxane content to the thermal stability of meta-aramid fiber insulation paper. Materials 2018, 11, 2317. [CrossRef]

31. Wang, X.; Tang, C.; Wang, Q.; Li, X.; Hao, J. Selection of optimal polymerization degree and force field in the molecular dynamics simulation of insulating paper cellulose. Energies 2017, 10, 1377. [CrossRef]

32. Tang, C.; Zhang, S.; Wang, X.; Hao, J. Enhanced mechanical properties and thermal stability of cellulose insulation paper achieved by doping with melamine-grafted nano-SiO 2 . Cellulose 2018, 25, 3619-3633. [CrossRef]

33. Lundgaard, L.E.; Hansen, W.; Ingebrigtsen, S. Ageing of mineral oil impregnated cellulose by acid catalysis. IEEE Trans. Dielectr. Electr. Insul. 2008, 15, 540-546. [CrossRef]

34. Jeyranpour, F.; Alahyarizadeh, G.; Minuchehr, A. The thermo-mechanical properties estimation of fullerene-reinforced resin epoxy composites by molecular dynamics simulation-A comparative study. Polymer 2016, 88, 9-18. [CrossRef]

35. Sun, H. COMPASS: An ab initio force-field optimized for condensed-phase applications overview with details on alkane and benzene compounds. J. Phys. Chem. B 1998, 102, 7338-7364. [CrossRef]

36. Wang, X.; Tang, C.; Wang, Q.; Lu, Y.; Liu, X. Thermal stability improvement of polysiloxane-grafted insulating papercellulose in micro-water environment. AIP Adv. 2018, 8, 1050071.

37. Tang, C.; Li, X.; Li, Z.; Hao, J. Interfacial hydrogen bonds and their influence mechanism on increasing the thermal stability of nano-SiO ${ }_{2}$-modified meta-aramid fibres. Polymers 2017, 9, 504. [CrossRef] [PubMed]

38. Yanchun, Y.; Wei, Z.; Jijun, X.; Xiang, G.; Gen, T.; Jian, Z.; Heming, X. Molecular dynamics simulation of binding energies and mechanical properties of energetic systems with four components. Acta Chim. Sin. 2010, 68, 1181-1187.

39. Fu, Y.Z.; Liu, Y.Q.; Lan, Y.H. Molecular simulation on the glass transition of polypropylene. Polym. Mater. Sci. Eng. 2009, 25, 53-56.

40. Wu, J.L. Elasticity; Higher Education Press: Beijing, China, 2001.

41. Nimmanpipug, P.; Tashiro, K.; Maeda, Y.; Rangsiman, O. Factors governing the three-dimensional hydrogen bond network structure of poly(m-phenylene isophthalamide) and a series of its model compounds: (1) systematic classification of structures analyzed by the X-ray diffraction method. J. Phys. Chem. B 2002, 106, 6842-6848. [CrossRef]

42. Villar-Rodil, S.; Paredes, J.I.; Martínez-Alonso, A.; Tascón, J.M.D. Atomic force microscopy and infrared spectroscopy studies of the thermal degradation of nomex aramid fibers. Chem. Mater. 2012, 13, 4297-4304. [CrossRef]

43. Li, G.L. Organic Silicon Polymer Chemistry, 1st ed.; Science Press: Beijing, China, 1998.

44. Yang, Z.; Feng, L.; Diao, S.; Feng, S.; Zhang, C. Study on the synthesis and thermal degradation of silicone resin containing silphenylene units. Thermochim. Acta 2011, 521, 170-175. [CrossRef]

45. Tian, F.; Yang, C.; He, L.; Han, B.; Wang, Y.; Lei, Q. Recent research advancement in dielectric properties and the corresponding mechanism of polymer/inorganic nanocomposite. Rransactions China Electrotech. Soc. 2011, 26, 1-12.

46. Chen, J.D.; Liu, Z.Y. Dielectric Physics; China Machine Press: Beijing, China, 1988.

47. Stevens, G.C.; Freebody, N.A.; Hyde, A.; Perrot, F.; Szkoda-Giannaki, I.; Vaughan, A.S.; Virtanen, S.; Baker, P.; Bon, S.; Coles, S.R.; et al. Balanced nanocomposite thermosetting materials for HVDC and AC applications. In Proceedings of the 2015 IEEE Electrical Insulation Conference (EIC), Seattle, WA, USA, 7-10 June 2015; pp. 193-196. [CrossRef]

48. Ishimoto, K.; Tanaka, T.; Ohki, Y.; Sekiguchi, Y.; Murata, Y.; Gosyowaki, M. Comparison of dielectric properties of low-density polyethylene $/ \mathrm{MgO}$ composites with different size fillers. In Proceedings of the 2008 Annual Report Conference on Electrical Insulation and Dielectric Phenomena, Quebec, QC, Canada, 26-29 October 2008; pp. 208-211. [CrossRef]

49. Wang, W.; Li, S.; Tang, F.; Li, J. Characteristics on breakdown performance of polyethylene/silica dioxide nano-composites. In Proceedings of the 2012 Annual Report Conference on Electrical Insulation and Dielectric Phenomena, Montreal, QC, Canada, 14-17 October 2012; pp. 521-524.

50. Li, J.; Liang, H.; Xiao, M.; Du, B.; Takada, T. Mechanism of deep trap sites in epoxy/graphene nanocomposite using quantum chemical calculation. IEEE Trans. Dielectr. Electr. Insul. 2019, 26, 1577-1580. [CrossRef]

51. Maex, K.; Baklanov, M.R.; Shamiryan, D.; Lacopi, F.; Brongersma, S.H.; Yanovitskaya, Z.S. Low dielectric constant materials for microelectronics. J. Appl. Phys. 2003, 93, 8793-8841. [CrossRef] 
52. Böttcher, C.J.F.; Bordewijk, P. Theory of Electric Polarization, Volume II: Dielectric in Time-Dependent Fields; Elsevier: Amsterdam, The Netherlands, 1978.

53. Li, C.; Strachan, A. Cohesive energy density and solubility parameter evolution during the curing of thermoset. Polymer 2018, 135, 162-170. [CrossRef]

54. Chang, K.-S.; Chung, Y.-C.; Yang, T.-H.; Lue, S.J.; Tung, K.-L.; Lin, Y.-F. Free volume and alcohol transport properties of PDMS membranes: Insights of nano-structure and interfacial affinity from molecular modeling. J. Membr. Sci. 2012, 417-418, 119-130. [CrossRef]

55. Zhang, W.; Li, H.; Gao, L.; Zhang, Q.; Zhong, W.; Sui, G.; Yang, X. Molecular simulation and experimental analysis on thermal and mechanical properties of carbon nanotube/epoxy resin composites with different curing agents at high-low temperature. Polym. Compos. 2017, 39, E945-E954. [CrossRef] 